Research Article

\title{
Couple Stress Hybrid Nanofluid Flow through a Converging- Diverging Channel
}

\author{
Malik Zaka Ullah, ${ }^{1}$ Dina Abuzaid, ${ }^{1}$ M. Asma, ${ }^{2}$ and Abdul Bariq $\mathbb{D}^{3}$ \\ ${ }^{1}$ Department of Mathematics, Faculty of Science, King Abdulaziz University, Jeddah 21589, Saudi Arabia \\ ${ }^{2}$ Institute of Mathematical Sciences, Faculty of Science, University of Malaya, 50603 Kuala Lumpur, Malaysia \\ ${ }^{3}$ Department of Mathematics, Laghman University, Mehtarlam 2701, Laghman, Afghanistan
}

Correspondence should be addressed to Abdul Bariq; abdulbariq.maths@lu.edu.af

Received 4 September 2021; Revised 29 September 2021; Accepted 30 September 2021; Published 10 November 2021

Academic Editor: Amir Khan

Copyright (c) 2021 Malik Zaka Ullah et al. This is an open access article distributed under the Creative Commons Attribution License, which permits unrestricted use, distribution, and reproduction in any medium, provided the original work is properly cited.

\begin{abstract}
This research work is aimed at scrutinizing the mathematical model for the hybrid nanofluid flow in a converging and diverging channel. Titanium dioxide and silver are considered solid nanoparticles while blood is considered as a base solvent. The couple stress fluid model is essentially used to describe the blood flow. The radiation terminology is also included in the energy equation for the sustainability of drug delivery. The aim is to link the recent study with the applications of drug delivery. It is well-known from the available literature that the combination of $\mathrm{TiO}_{2}$ with any other metal can vanish more cancer cells than $\mathrm{TiO}_{2}$ separately. Governing equations are altered into the system of nonlinear coupled equations the similarity variables. The Homotopy Analysis Method (HAM) analytical approach is applied to obtain the preferred solution. The influence of the modeled parameters has been calculated and displayed. The confrontation to wall shear stress and hybrid nanofluid flow growth as the couple stress parameter rises which improves the stability of the base fluid (blood). The percentage (\%) increase in the heat transfer rate with the variation of nanoparticle volume fraction is also calculated numerically and discussed.
\end{abstract}

\section{Introduction}

The flow of fluids in converging/diverging channels has particularly significant applications in science and technology, such as flows in cavities and channels. The converging/divergent channels also relate to the blood flow in the arteries and capillaries. The stretching converging and diverging channels are also very significant to the blood flow due to the occurrence of stress effects. The researcher has worked in the same model for other industrial applications. Sheikholeslami et al. [1] demonstrated the effect of nanoparticles considering Jeffery fluid. Turkyilmazoglu [2], Dogonchi and Ganji [3], Xia et al. [4], and Mishra et al. [5] have considered the same model for the fluid flow using the concept of shrinking/stretching in converging/diverging channels.

Nanotechnology has refined and expanded the horizons of today's scientific world owing to its unpredicted results occurring in the field of energy, biotechnology, drugs, and therapeutics. It has also been demonstrated that stenosis is a damaging and potentially fatal disease, so researchers attempted to eliminate the problem using nanotechnology. Researchers believe that nanotechnology can deliver innovation in treating these kinds of problems since nanoparticles can pass through tissues and cells. Following that, there is a noticeable increase in research related to the advanced progress of nanoparticles in drugs [6-9].

Shahzadi and Bilal [10] pioneered nanoparticles by revealing their dynamic and abnormal properties. Nadeem and Ijaz [11] described the use of nanoparticles to transport blood through a stenosis artery with a permeable wall. Ellahi et al. [12] reported blood flow to arteries consisting of the composite when nanoparticles were used. Nadeem and Ijaz [13] studied the effect of nanoparticles on stenotic artery hemodynamics and found them to be very helpful in reducing wall pressure with a shear rate.

There is dispersion of more nanoparticles with different thermophysical properties from hybrid nanofluids that have attracted researchers because they are widely used in the 
fields of energy and medicine [14]. The case of bionanotechnology, which is a renovation and an open and innovative horizon in medicine, is one of the most auspicious applications of hybrid fluids. Numerous studies have demonstrated the effectiveness of nanoparticles in tumor targeting, therapy, and diagnosis process. Many studies have shown how effective nanoparticles are in tumor targeting, diagnosis, and treatment. It should be noted that nanoparticles have eliminated some of the shortcomings of traditional chemotherapy [15]. Liu et al. [16] investigated the use of $\mathrm{Pt} / \mathrm{TiO}_{2}$ and $\mathrm{Au} / \mathrm{TiO}{ }_{2}$ nanocomposites, which are useful for cancer cell treatment. It was observed that the combination of $\mathrm{TiO}_{2}$ with any other metal can vanish more cancer cells than $\mathrm{TiO}_{2}$ separately. Silver has a wide range of biomedical uses due to its exclusive properties. The product containing silver is usually used for antimicrobial activity versus a broad spectrum of microorganisms. Moreover, experimental data suggest that Ag nanoparticles are a more ecological and biocompatible substitute to standard anticancer medicines [17].

Blood, the most important biological fluid, is a liquid composed of various cell types suspended in a matrix of aqueous fluid (the plasma). It should be noted that red blood cells in plasma contribute to rotary motion in the occurrence of a velocity gradient. Body tissues have an angular gyration moment as well as an angular orbital moment. As a result, blood may be assumed a non-Newtonian fluid with a constant density. Stokes' theory is one of several polar fluid theories that take into consideration [18].

Couple stress fluid applications in biological problems are gaining popularity, and they are critical from both a theoretical and practical standpoint. Blood flow can be controlled with adequate couple stress. The theory of couple stress is first time introduced by Stokes [19] in the blood flow and claimed that blood is very reasonably flowing in the vessels due to the occurrence of the couple stresses. Devakar and Iyengar [20] suggested using a couple-stress term to regulate blood flow through the human system. Similarly, the idea was further extended by Devakar and Iyengar using the isothermal conditions and have found the exact solution. Recently, Saeed et al. [21], Ahmad et al. [22], and Gul et al. $[23,24]$ have used the couple stress fluid terminology in the hybrid nanofluids for drug transport and medication. They have also studied the heat transfer enhancement effect on the blood flow in various geometries.

In the light of the above discussion, the novelty of this study is highlighted as follows:

(i) According to the best of the author's knowledge, no one has tried to investigate the flow through a converging/diverging stretchable/shrinkable channel with blood as the base fluid and $\mathrm{TiO}_{2}-\mathrm{Ag}$ as nanoparticles

(ii) This article examines a suitable background of couple stress hybrid nanofluid flow through converging/diverging stretchable/shrinkable channels

(iii) Heat absorption/omission and thermal radiation terminologies also strengthen the novelty of the work (iv) The system of equations is then analytically solved by HAM

(v) The statistical analysis is also performed and presented through bar charts

\section{Formulation}

Assume the steady, laminar, incompressible, and couple stress $\left(\mathrm{TiO}_{2}-\mathrm{Ag}\right)$ hybrid nanofluid, while the fluid motion is caused by the thermal radiation and a source or sink among the binary contracting/expanding channel, such that $2 \alpha$ is the angle between them. The walls of the channel are also assumed to be stretchable along the radial direction.

$$
u=\frac{s}{r}=u_{w}
$$

Here, $u=u(r, \theta), s$ stands for the velocity of the hybrid nanofluids and extending/contracting phenomena, respectively. The conditions $(\alpha>0, \alpha<0)$ are used to show that the channels are divergent and convergent correspondingly. The velocity for the fluid motion is the function of both $(r$ $, \theta)$. The couple stress terminology is imposed to the flow field whereas the other assumptions of [3-5] are used; the basic constituent dimensional equations of the hybrid nanofluid are taken into account.

$$
\begin{gathered}
\rho_{\mathrm{hnf}}\left(\frac{u}{r}+\frac{\partial u}{\partial r}\right)=0 \\
\rho_{\mathrm{hnf}}\left(u \frac{\partial u}{\partial r}\right)+\left(\frac{\partial P}{\partial r}\right)=\mu_{\mathrm{hnf}}\left(\frac{\partial}{\partial r}\left(\frac{u}{r}+\frac{\partial u}{\partial r}\right)+\frac{1}{r^{2}} \frac{\partial^{2} u}{\partial \theta^{2}}\right)-\eta_{0} \frac{\partial^{4} u}{\partial r^{4}} \\
\frac{\partial P}{\partial \theta}-2 \mu_{\mathrm{hnf}} \frac{1}{r^{2}} \frac{\partial u}{\partial \theta}=0 \\
\left(\rho C_{p}\right)_{\mathrm{hnf}}\left(u \frac{\partial T}{\partial r}\right)=k_{\mathrm{hnf}}\left(\frac{1}{r} \frac{\partial}{\partial r}\left(r \frac{\partial T}{\partial r}\right)+\frac{1}{r^{2}} \frac{\partial^{2} T}{\partial \theta^{2}}\right) \\
-\frac{1}{r}\left(\frac{1}{r} \frac{\partial}{\partial \theta}\left(q_{\theta, \mathrm{rad}}\right)+\frac{\partial}{\partial r}\left(r q_{r, \mathrm{rad}}\right)\right)
\end{gathered}
$$

The pressure of fluid, electromagnetic field, and radiative heat flux are presented by $P, B_{0}, q_{r, \text { rad }}, q_{\theta \text {,rad }}$.

The radiation terms are further written as

$$
\begin{aligned}
& q_{\theta, \mathrm{rad}}=\left(\frac{-16 \sigma^{*} T_{0}^{3}}{3 k_{f^{*}}}\right) \frac{\partial T}{\partial \theta}, \\
& q_{r, \mathrm{rad}}=\left(\frac{-16 \sigma^{*} T_{0}^{3}}{3 k_{f^{*}}}\right) \frac{\partial T}{\partial r} .
\end{aligned}
$$

Here, $k_{n f^{*}}$ and $\sigma^{*}$ are the absorption term and StefanBoltzmann constants. 
Table 1: Properties of $\mathrm{TiO}_{2}$ and blood nanofluid [18].

\begin{tabular}{lc}
\hline Viscosity & $\mu_{n f}=\mu_{f} /\left(1-\phi_{1}\right)^{2.5}$ \\
Density & $\rho_{n f}=\left\{\rho_{f}\left(1-\phi_{1}\right)+\rho_{f} \phi_{1}\left(\rho_{\mathrm{TiO}_{2}}\right)\right\}$ \\
Specific heat & $\left(\rho C_{p}\right)_{n f}=\left[\left(\rho C_{p}\right)_{f}\left(1-\phi_{1}\right)+\phi_{1}\left(\left(\rho C_{p}\right)_{\mathrm{TiO}_{2}}\right)\right]$ \\
Thermal conductivity & $k_{n f}=k_{f}\left(k_{\mathrm{TiO}_{2}}+2 k_{f}+2 \phi_{1}\left(k_{f}-k_{\mathrm{TiO}_{2}}\right)\right)^{-1}\left(k_{\mathrm{TiO}_{2}}+2 k_{f}-2 \phi_{1}\left(k_{f}-k_{\mathrm{TiO}_{2}}\right)\right)$
\end{tabular}

TABLE 2: Various thermophysical properties of $\mathrm{TiO}_{2}-\mathrm{Ag}$ are stated as [18].

\begin{tabular}{lc}
\hline Viscosity & $\mu_{\mathrm{hnf}}=\mu_{f}\left(1-\phi_{1}\right)^{-2.5}\left(1-\phi_{2}\right)^{-2.5}$ \\
Density & $\rho_{\mathrm{hnf}}=\left(1-\phi_{2}\right)\left\{\phi_{1} \rho_{\mathrm{TiO}_{2}}+\left(1-\phi_{1}\right) \rho_{f}\right\}+\phi_{2} \rho_{\mathrm{TiO}_{2}}$ \\
Specific heat & $\left(\rho C_{p}\right)_{\mathrm{hnf}}=\left(\rho C_{p}\right)_{f}\left(1-\phi_{2}\right)\left(1-\phi_{1}\right)+\phi_{1}\left(\left(\rho C_{p}\right)_{\mathrm{TiO}_{2}}\right)+\phi_{2}\left(\left(\rho C_{p}\right)_{\mathrm{Ag}}\right)$ \\
Thermal conductivity & $k_{\mathrm{hnf}}=k_{f}\left\{\left(k_{\mathrm{TiO}_{2}}+2 k_{n f}+2 \phi_{2}\left(k_{n f}-k_{\mathrm{TiO}_{2}}\right)\right)^{-1}\left(k_{\mathrm{TiO}_{2}}+2 k_{n f}-2 \phi_{2}\left(k_{n f}-k_{\mathrm{TiO}}\right)\right)\right\} \times$ \\
& $\left\{\left(k_{\mathrm{Ag}}+2 k_{f}-2 \phi_{1}\left(k_{f}-k_{\mathrm{Ag}}\right)\right)^{-1}\left(k_{\mathrm{Ag}}+2 k_{f}-2 \phi_{1}\left(k_{f}-k_{\mathrm{Ag}}\right)\right)\right\}$
\end{tabular}
have

Putting the values of equation (7) into equation (5), we

$$
\left(\rho C_{p}\right)_{\mathrm{hnf}}\left(u \frac{\partial T}{\partial r}\right)=\left(k_{\mathrm{hnf}}+\frac{16 \sigma^{*} T_{\infty}^{3}}{3 k_{f}^{*}}\right)\left[\frac{1}{r} \frac{\partial}{\partial r}\left(r \frac{\partial T}{\partial r}\right)+\frac{1}{r^{2}} \frac{\partial^{2} T}{\partial \theta^{2}}\right] .
$$

In the above equations, $\eta_{0}$ is the couple stress term; also, $\rho_{\mathrm{hnf}}, \mu_{\mathrm{hnf}},\left(\rho C_{p}\right)_{\mathrm{hnf}}$, and $k_{\mathrm{hnf}}$ represent density, viscosity, density, and specific heat; the thermal conductivity of the hybrid nanofluids such that hnf stands for hybrid nanofluid.

2.1. Properties of the Materials. Initially, nanoparticles (titanium) are dispersed in the bloodstream (base fluid) to produce one (mono-nano fluid). (Silver) is then distributed as an additional nanoparticle to form the (hybrid nanofluid). On this occasion, $\mathrm{TiO}_{2}$ represents (titanium dioxide nanomaterial) and silver (Ag nanoparticles) and subscript $f$ describes blood (base fluid). In Tables 1 and 2, $\phi_{1}$ and $\phi_{2}$ state the volume fraction of $\mathrm{TiO}_{2}$ and $\mathrm{Ag}$ nanoparticles, where $\phi_{1}=\phi_{2}=0$ refers to the base fluid.

2.2. Initial and Boundary Conditions. The auxiliary conditions at boundaries are

$$
\left.\begin{array}{l}
u=r^{-1} u_{c}, \frac{\partial T}{\partial \theta}=u \frac{\partial T}{\partial r}=0, \text { at } \theta \longrightarrow 0, r \neq 0 \\
u=r^{-1} s=u_{w}, T=r^{-2} T_{w} \text { as } \theta \longrightarrow \pm \alpha
\end{array}\right\} .
$$

2.3. Introduction of Nondimensional Variables. In the case of the radial flow, equation (1) reduced to

$$
F(\theta)=r u(r, \theta)
$$

The nondimensional transformation is defined as

$$
F(\eta)=\left(u_{c}\right)^{-1} F(\theta), \Theta(\eta)=\left(r^{2} T\right) T_{w}^{-1}, \quad \eta=\theta \alpha^{-1}
$$

The use of (10) and (11) and thermophysical properties alter equations (3)-(5) in the simplified form as

$$
\begin{gathered}
F^{\prime \prime \prime}+2 \alpha \operatorname{Re} \frac{\rho_{\mathrm{hnf}}}{\rho_{f}} \frac{\mu_{f}}{\mu_{\mathrm{hnf}}} F F^{\prime}+4 \alpha^{2} F^{\prime}-24 \alpha^{2} k^{*} F^{\prime}=0, \\
\left(\frac{k_{\mathrm{hnf}}}{k_{f}}+R d\right) \Theta^{\prime \prime}+\alpha^{2}\left[\frac{\left(\rho C_{p}\right)_{\mathrm{hnf}}}{\left(\rho C_{p}\right)_{f}} 2 \operatorname{Pr} F \Theta+4+4 R d \Theta\right]=0 .
\end{gathered}
$$

The simplified form of the physical conditions are stated as

$$
\left.\begin{array}{l}
F=1, \Theta^{\prime}=F^{\prime}=0, \text { at } \eta=0 \\
F=\lambda, \Theta=1, \text { at } \eta= \pm 1
\end{array}\right\}
$$

Here, $\lambda=s / u_{c}>0$ is the stretching parameter, $\lambda=s / u_{c}$ $<0$ is a shrinking parameter, $R d=16 \sigma^{*} T^{3}{ }_{\infty} / 3 k_{f} k_{f}^{*}$ is radiation parameter, $\operatorname{Re}=r \alpha u_{c} / v_{f}$ is the Reynolds number, $\operatorname{Pr}$ $=\left(\mu C_{p}\right)_{f} / k_{f}$ is the Prandtl number, and $k^{*}=\eta_{0} / \mu r^{2}$ is the couple stress parameter.

2.4. Drag Force and Heat Transfer Rate. The significant parameters of curiosity are defined as

$$
u_{c}^{2} \rho_{f} C_{f}=\left.\mu_{\mathrm{hnf}}\left(\frac{1}{r} \frac{\partial u}{\partial \theta}\right)\right|_{\theta= \pm \alpha},
$$




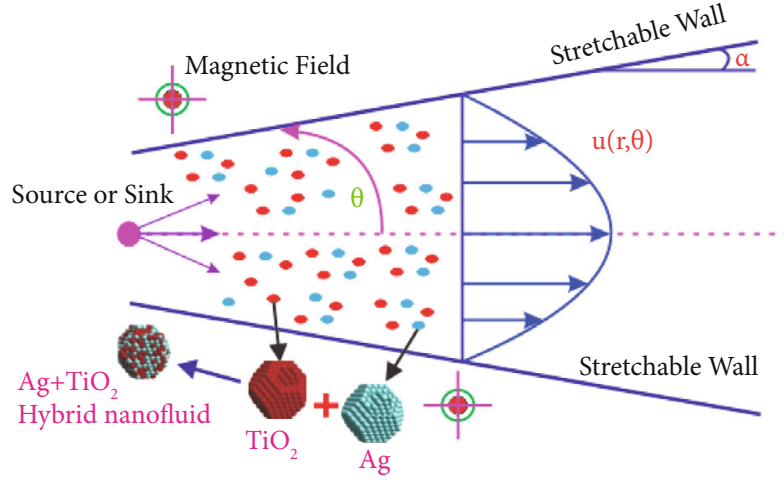

(a)

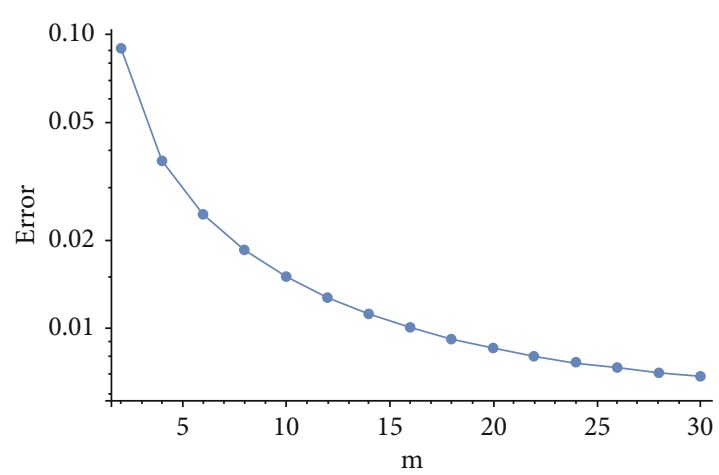

(b)

Figure 1: (a) The geometry of the problem and (b) the HAM method.

$$
T_{w} \mathrm{Nu}=\left.\left(\frac{16 \sigma^{*} T_{\infty}^{3}}{3 k_{f} k_{f}^{*}}+\frac{k_{\mathrm{hnf}}}{k_{f}}\right) \frac{\partial T}{\partial \theta}\right|_{\theta= \pm \alpha} .
$$

The alteration used for equation (16) and the simplified form is attained as

$$
\begin{aligned}
C_{f} & =\frac{1}{\operatorname{Re}} \frac{\mu_{\mathrm{hnf}}}{\mu_{f}}\left|f^{\prime}( \pm 1)\right|, \\
\mathrm{Nu} & =\frac{1}{\alpha}\left|\left(R d+\frac{k_{\mathrm{hnf}}}{k_{f}}\right) \Theta^{\prime}( \pm 1)\right| .
\end{aligned}
$$

\section{Solution Methodology}

The series solution is one of the valued methods to handle nonlinear problems. Nonlinear problems usually arise in the field of science and engineering. HAM is one of the latest and fast convergence techniques and is frequently used in the solution of nonlinear and coupled equations. The BVPh 1.0 and $\mathrm{BVPh} 2.0$ are the latest packages of HAM that enhance the convergence of the proposed problems. These packages are very helpful in the rapid convergence, and one can use the BVPh 2.0 package up to the 100th iterations easily. The idea of HAM was first introduced by Liao [25]. The idea is further improved by the same author by introducing the new packages [26]. These packages are frequently used like [27-32].

The feedback problem (12)-(18) was resolved by the HAM-BVPh 2.0 technique. The estimate of the iterations is utilized up to the 30th order. The trial solution or initial solution is required for the HAM solution. The zerothorder solution is obtained as

$$
F_{0}(\eta)=1-\eta^{2}(1-\lambda) \& \Theta_{0}(\eta)=1
$$

Equations (12)-(14) are set under the planned packaging and presented as
TABle 3: Numerous thermophysical properties are defined as [18].

\begin{tabular}{lccc}
\hline Solid material and base fluid & $c_{p}(\mathrm{~J} / \mathrm{kgK})$ & $k(\mathrm{~W} / \mathrm{mK})$ & $\rho\left(\mathrm{Kg} / \mathrm{m}^{3}\right)$ \\
\hline $\mathrm{TiO}_{2}$ (titanium dioxide) & 686.2 & 8.954 & 4250 \\
Silver: Ag & 235 & 429 & 10500 \\
Blood & 3594 & 0.492 & 1063
\end{tabular}

$$
\begin{aligned}
& x_{p}^{F}=\frac{1}{p+1} \sum_{k=1}^{p}\left[\Phi_{F}\left(\sum_{j=1}^{l} F(\eta)\right)_{\eta=k j p}\right]^{2}, \\
& x_{p}^{\Theta}=\frac{1}{p+1} \sum_{k=1}^{p}\left[\left(\sum_{j=1}^{l} F(\eta)\right)_{\eta=k j p} \Phi_{\Theta}\left(\sum_{j=1}^{l} \Theta(\eta)\right)_{\eta=k j p}\right]^{2} .
\end{aligned}
$$

The sum of the two components in the form of square residual errors is displayed as

$$
\chi_{p}^{\text {Total }}=\chi_{p}^{F}+\chi_{l p}^{\Theta}
$$

The numerical results of the converging parameter are obtained as

$$
\begin{aligned}
& 0.130021 \leq h_{f} \leq-1.203417 \\
& 0.120432 \leq h_{\theta} \leq-0.8992310
\end{aligned}
$$

The range of convergence control parameters is used to find out the physical and numeric results.

\section{Results and Discussion}

The flow of the blood-based hybrid nanofluid consisting of $\mathrm{TiO}_{2}$ and $\mathrm{Ag}$ has been considered in the converging and diverging channel. The heat transfer mechanism and medication are the main purposes of the proposed model. The main finding of the obtained results is shown physically and numerically. The geometry of the problem and convergence controlling sketches are demonstrated in Figures 1(a) 
TABLE 4: Comparison between the present work with previous work considering common parameters only.

\begin{tabular}{ccccccccc}
\hline & $F^{\prime \prime}( \pm 1)$, & $F^{\prime \prime}( \pm 1)$ & $F^{\prime \prime}( \pm 1)$ & $F^{\prime \prime}( \pm 1)$ & $F^{\prime \prime}( \pm 1)$, & $F^{\prime \prime}( \pm 1)$ & $F^{\prime \prime}( \pm 1)$ & $F^{\prime \prime}( \pm 1)$ \\
$\operatorname{Re}$ & $\left(\alpha=5^{0}\right)$ & $\left(\alpha=5^{0}\right)$ & $\left(\alpha=5^{0}\right)$ & $\left(\alpha=5^{0}\right)$ & $\left(\alpha=-5^{0}\right)$ & $\left(\alpha=-5^{0}\right)$ & $\left(\alpha=-5^{0}\right)$ & $\left(\alpha=-5^{0}\right)$ \\
& {$[3]$} & {$[4]$} & {$[5]$} & {$[$ Present $]$} & {$[3]$} & {$[4]$} & {$[5]$} & 0.77411 \\
\hline 1 & 1.86420 & 1.86431 & 1.86412 & 1.86701 & 0.77420 & 0.77432 & 0.77703 \\
2 & 1.88644 & 1.88652 & 1.88631 & 1.88912 & 0.79531 & 0.79542 & 0.79520 & 0.79821 \\
3 & 1.90422 & 1.90434 & 1.90412 & 1.907 & 0.80214 & 0.80223 & 0.80205 & 0.80501 \\
\hline
\end{tabular}

TABLE 5: Influence of parameter versus $-\operatorname{Re} C_{f}$.

\begin{tabular}{|c|c|c|c|c|c|c|}
\hline \multirow[t]{2}{*}{$\phi_{1}, \phi_{2}$} & \multirow[t]{2}{*}{$\mathrm{Re}$} & \multirow[t]{2}{*}{$k^{*}$} & $\begin{array}{r}-\operatorname{Re} C_{f} \\
(\alpha>0)\end{array}$ & \multirow[t]{2}{*}{$F(\eta)$} & $\begin{array}{r}-\operatorname{Re} C_{f} \\
(\alpha<0)\end{array}$ & $\begin{array}{r}-\operatorname{Re} C_{f} \\
(\alpha<0)\end{array}$ \\
\hline & & & $\mathrm{TiO}_{2}+\mathrm{Ag}$ & & $\mathrm{TiO}_{2}+\mathrm{Ag}$ & $\mathrm{TiO}_{2}$ \\
\hline 0.00 & 0.1 & 0.1 & 0.39586 & 0.37369 & 1.29495 & 1.27531 \\
\hline 0.01 & & & 0.41871 & 0.40651 & 1.27122 & 1.24531 \\
\hline \multirow[t]{5}{*}{0.01} & & & 0.434932 & 0.413731 & 1.28712 & 1.2661 \\
\hline & 0.2 & & 0.49638 & 0.47416 & 1.38542 & 1.36321 \\
\hline & 0.4 & & 0.597493 & 0.575294 & 1.49615 & 1.42402 \\
\hline & & 0.2 & 0.46735 & 0.44513 & 1.35621 & 1.13032 \\
\hline & & 0.4 & 0.515401 & 0.504021 & 1.40487 & 1.38612 \\
\hline
\end{tabular}

TABLE 6: Nusselt number $\mathrm{Nu}_{x}$ versus physical parameters.

\begin{tabular}{|c|c|c|c|c|c|}
\hline & & $-\mathrm{Nu}$ & $-\mathrm{Nu}$ & $-\mathrm{Nu}$ & $-\mathrm{Nu}$ \\
\hline \multirow[t]{2}{*}{$R d$} & $\phi_{1}, \phi_{2}$ & $\mathrm{TiO}_{2} \& \mathrm{Ag}$ & $\mathrm{TiO}_{2}$ & $\mathrm{TiO}_{2} \& \mathrm{Ag}$ & $\mathrm{TiO}_{2}$ \\
\hline & & $\alpha>0$ & $\alpha<0$ & $\alpha>0$ & $\alpha<0$ \\
\hline 0.2 & 0.01 & 9.41571 & 9.33102 & 11.39253 & 11.29123 \\
\hline 0.4 & & 9.47321 & 9.37321 & 11.50320 & 11.32134 \\
\hline \multirow[t]{3}{*}{0.6} & & 9.53631 & 9.41241 & 11.63103 & 11.53161 \\
\hline & 0.02 & 9.44645 & 9.24609 & 11.45708 & 11.38163 \\
\hline & 0.03 & 9.65435 & 9.58479 & 11.78790 & 11.67849 \\
\hline
\end{tabular}

and $1(\mathrm{~b})$. The thermophysical properties of the materials are presented in Tables $1-3$.

Table 4 shows the assessment of the current work with the available literature and the closed agreement to authenticate the validation of the problem. The drag force on the upper and lower walls is calculated for the embedding parameters and demonstrated in Table 5. The accumulative growth in the values of the constraints is used to keep the convergent range of the proposed problem. The drag force rises with the increment in these parameters $\left(\phi_{1}, \phi_{2}, \operatorname{Re}\right.$, and $\left.k^{*}\right)$ for both nanofluids and hybrid nanofluids. The calculated increase shows that the resistive force is more effective by using the hybrid nanofluid $\mathrm{TiO}_{2}+\mathrm{Ag}$ at both the lower and upper walls of the channels. Furthermore, the friction force is efficiently working in the converging channel as compared to the other one.

The heat transfer rate is calculated numerically using the embedded parameters, and the results are exhibited in Table 6 . The augmentation in the values of the parameters $R d, \phi_{1}$, and $\phi_{2}$ progresses the heat transfer rate ultimately. The attained results show that the heat transfer rate is more immediate by using the $\left(\mathrm{TiO}_{2}+\mathrm{Ag}\right)$ hybrid nanofluids. The heat transfer rate stimulates fluid motion by controlling the viscous effect. The $\mathrm{TiO}_{2}$ material works as the treatment material in cancer therapy while the stability in the blood is controlled through silver. The (\%) wise increase in the heat transfer rate versus the nanoparticle volume fraction has been calculated and displayed in Table 7 . The hybrid nanofluid improves the heat transfer analysis as compared to the other traditional fluids.

Figures 1-4 describe the influence of the physical parameters $\left(\phi_{1}, \phi_{2}, \operatorname{Re}, k^{*}\right)$, on the velocity $F(\eta)$ considering both converging and divergent channels. The parts $(a, b)$ and $(c$, d) of each figure show the same effect in 2D and 3D expressions. The parameters $\left(\phi_{1}, \phi_{2}\right)$ decline the fluid motion $F(\eta)$ for its higher values using the extending/convergent and contracting/divergent channels as revealed in Figures 2(a)2(d). The nanoparticle dispersion in the base fluid enhances the viscous effect of the base solvent and improves the cohesive forces among the fluid molecules to resist the fluid motion. 
TABLE 7: \% analysis versus $\mathrm{Nu}_{x}$.

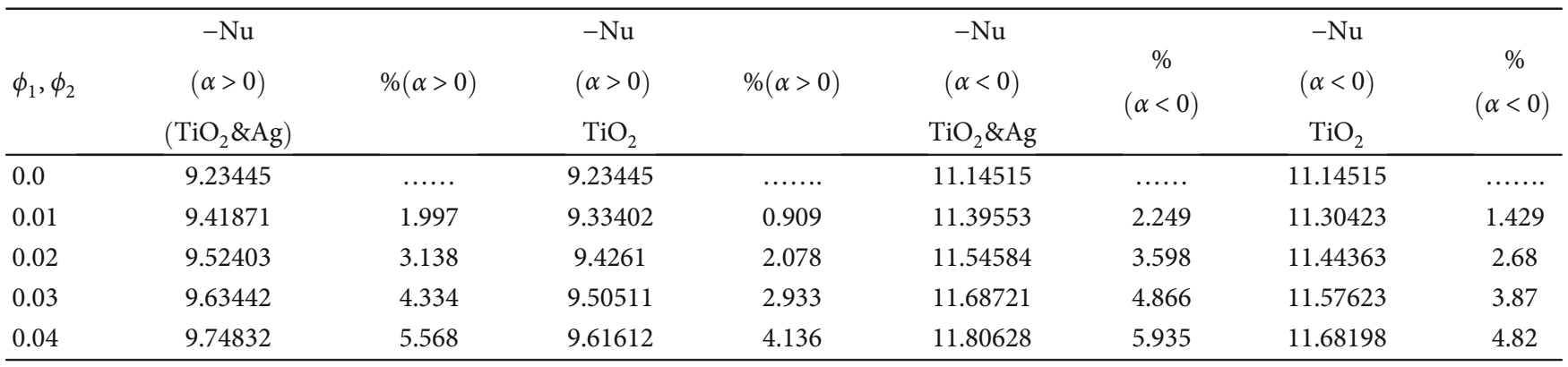

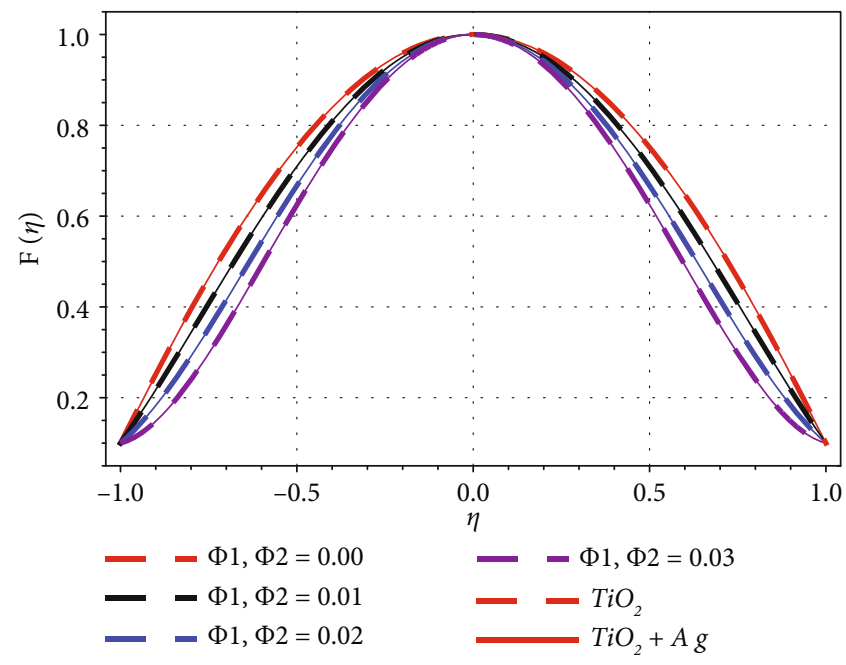

(a)

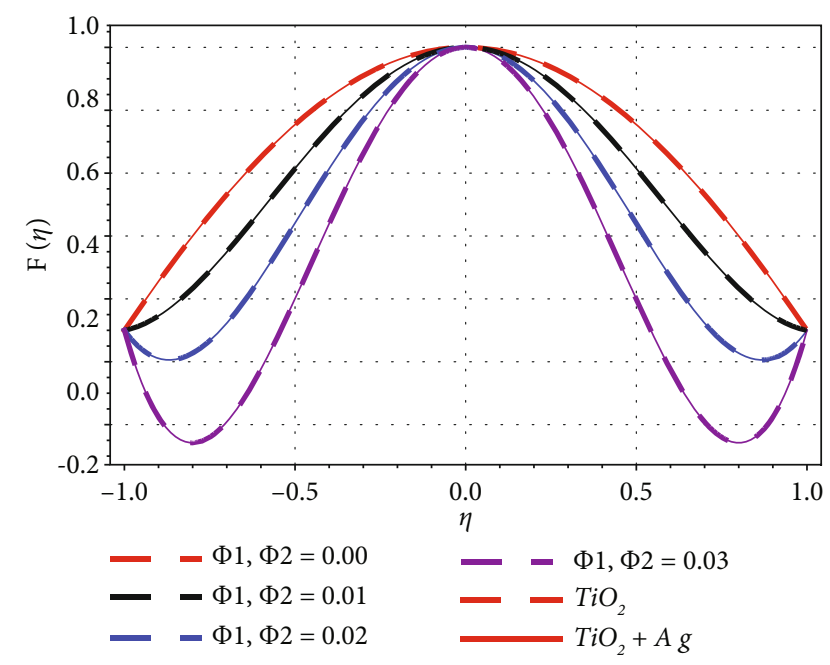

(c)

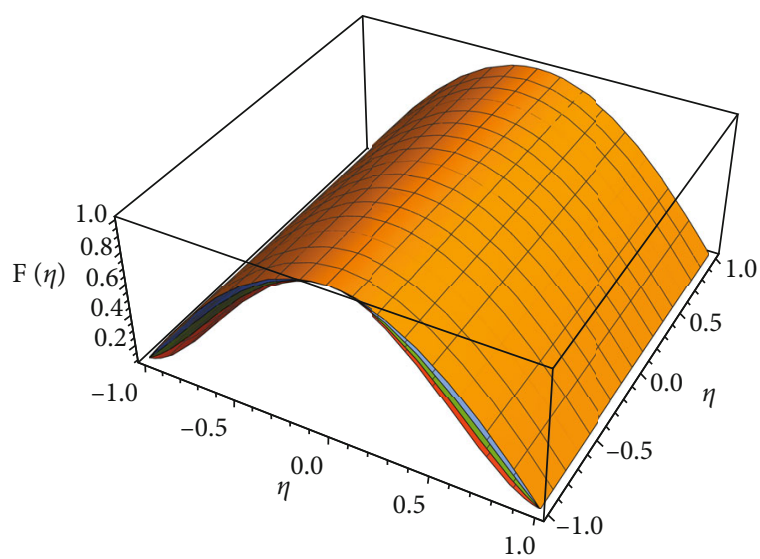

(b)

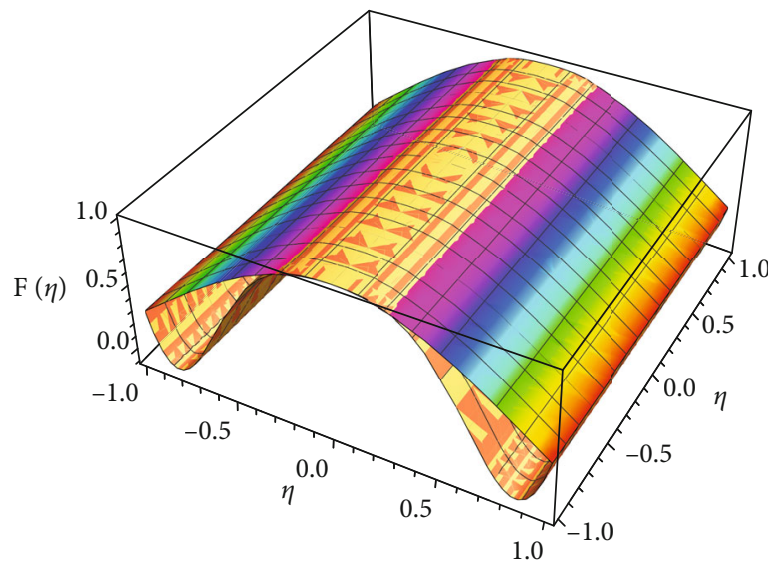

(d)

Figure 2: $F(\eta)$ versus $\phi_{1}, \phi_{2}$ in stretching/convergent circumstance with $\alpha=-5^{\circ}, 5^{\circ}$.

Figures 3(a)-3(d) show the effect of Re on $F(\eta)$ in the case of extending/convergence and narrowing/diverging. It can be witnessed that the increases in Reynolds number cause an increase in extending/convergent case, which can be observed from Figures 3(a) and 3(b) while a reverse result is obtained in the contracting/divergent case because the growth in Reynolds number causes a decline in the fluid motion, in this case, that can be seen in Figures 3(c) and $3(d)$. Figures 3(a) $-3(d)$ show the effect of Re on $F(\eta)$ in the case of extending/convergence and narrowing/diverging. It can be witnessed that the increases in Reynolds number cause an increase in extending/convergent case, which can 


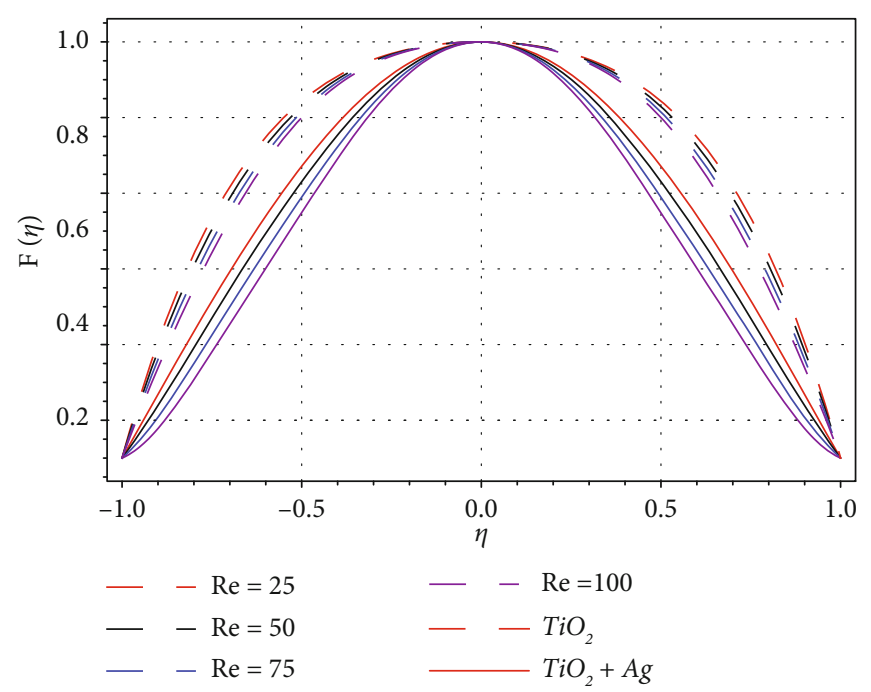

(a)

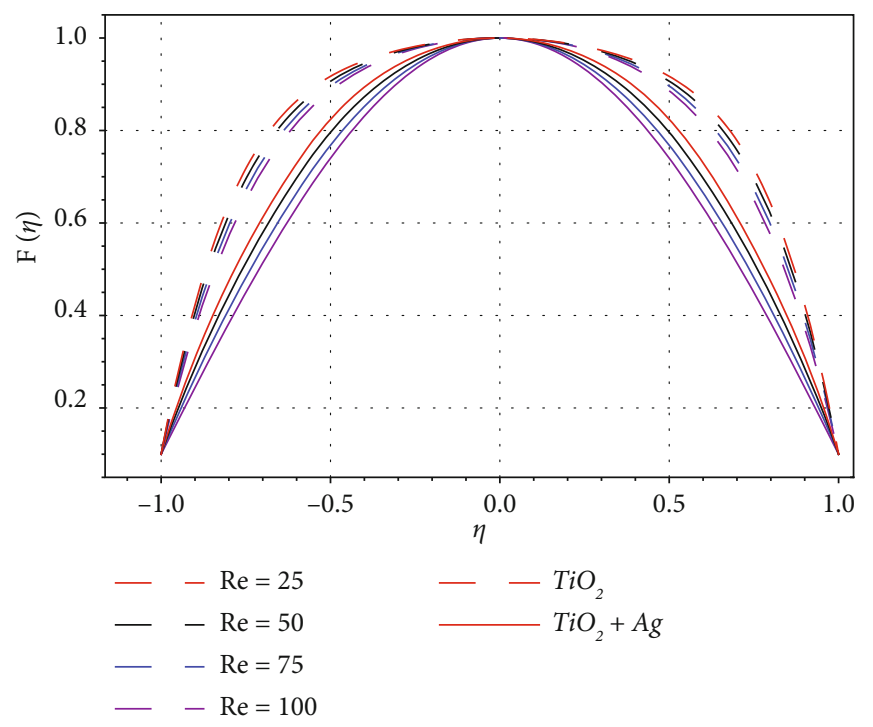

(c)

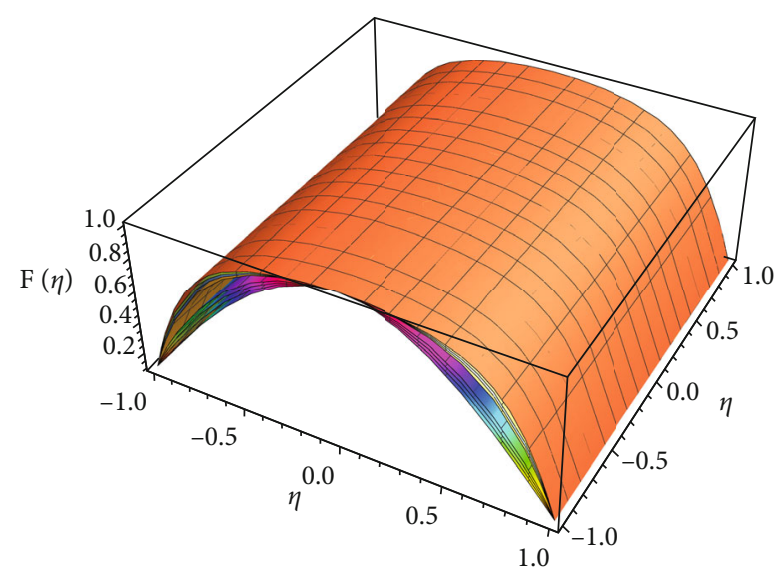

(b)

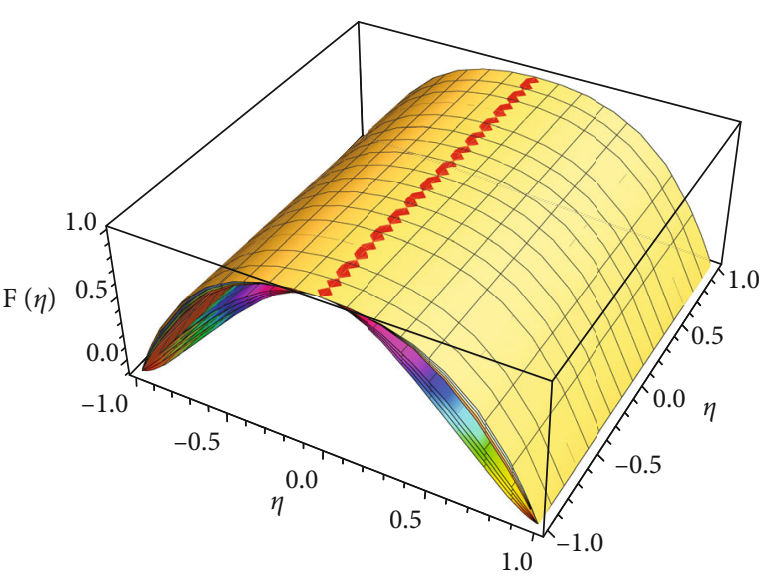

FIgURE 3: (a-d) $F(\eta)$ versus Re stretching/convergent circumstance with $\alpha=-5^{\circ}, 5^{\circ}$. 

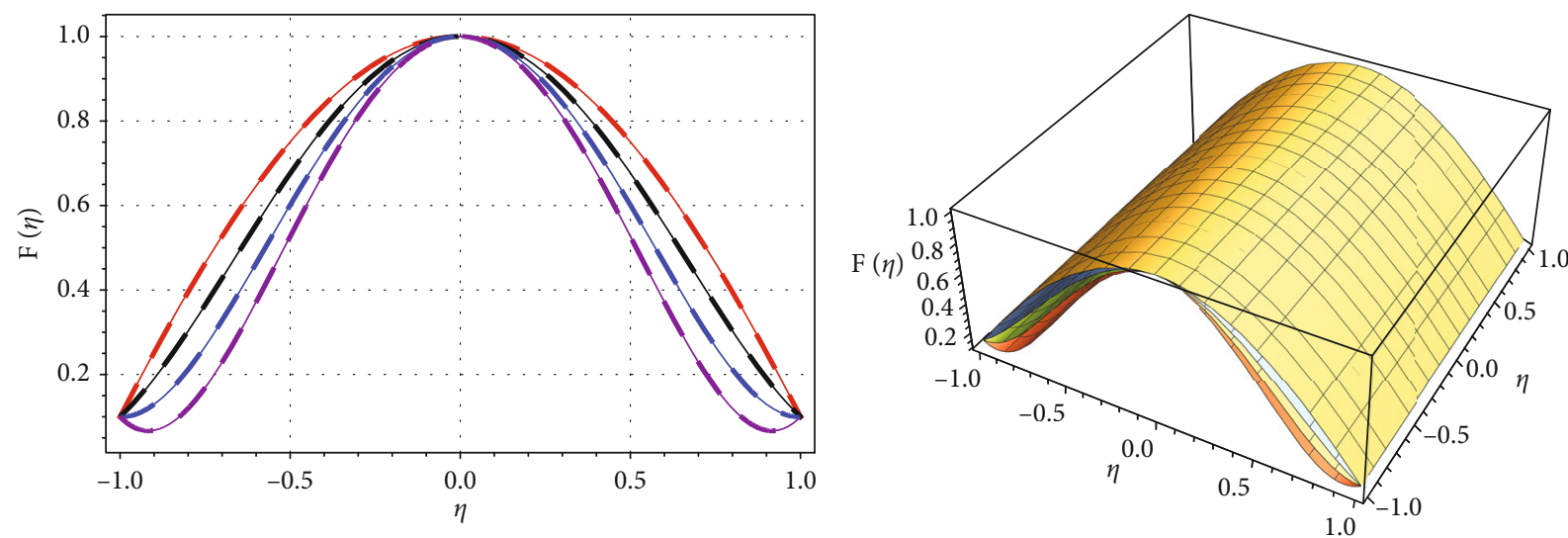

$$
\begin{array}{ll}
-k^{*}=0.1 & -\quad-\mathrm{TiO}_{2} \\
-k^{*} & =0.3 \\
-k^{*} & =0.6 \\
-\mathrm{TiO}_{2}+\mathrm{Ag} \\
-k^{*}=0.9
\end{array}
$$

(a)
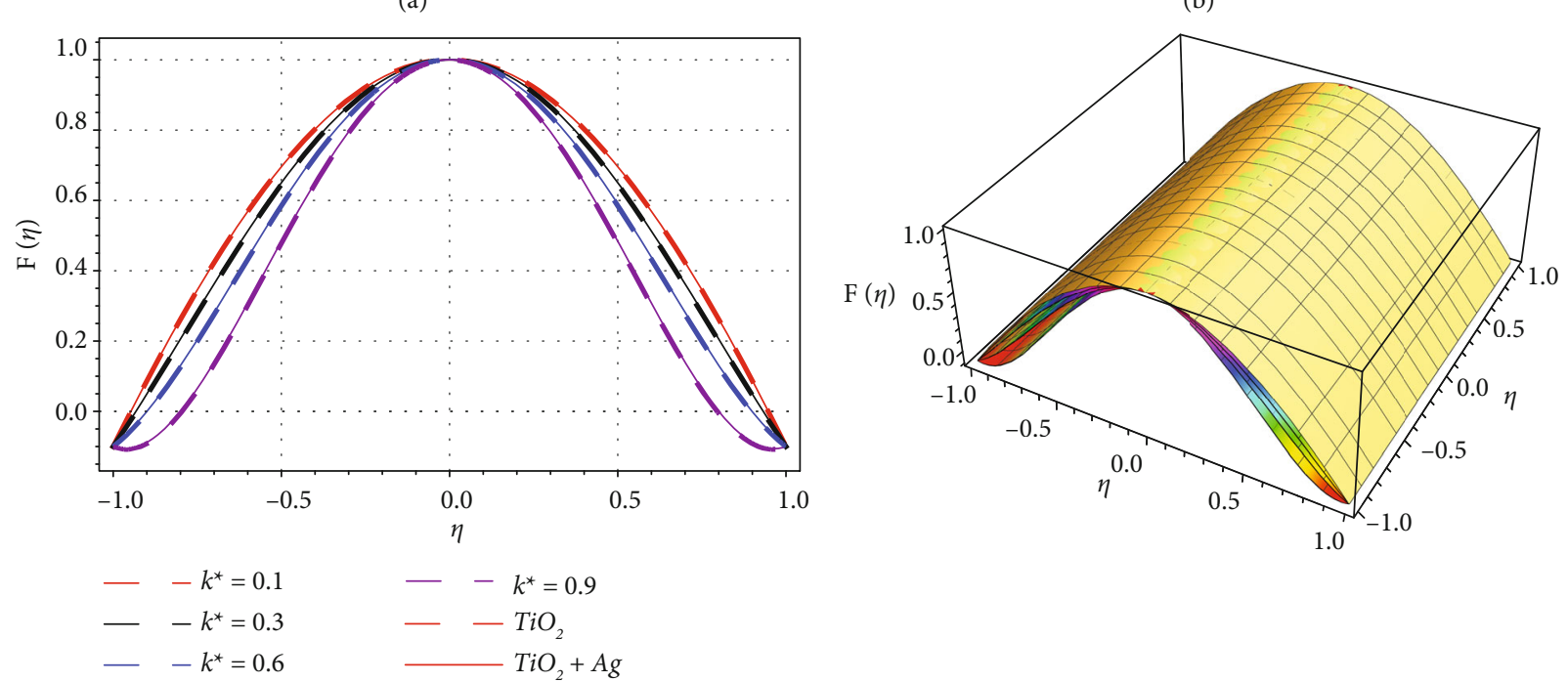

(c)

(d)

FIGURE 4: (a-d) $F(\eta)$ versus $k^{*}$ in stretching/convergent circumstance with $\alpha=-5^{\circ}, 5^{\circ}$. 


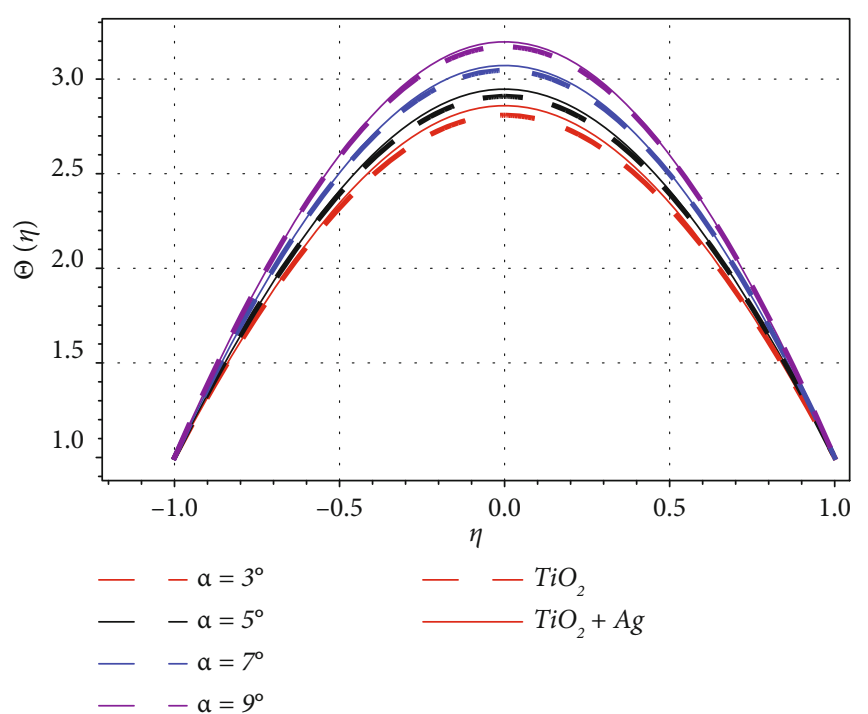

(a)

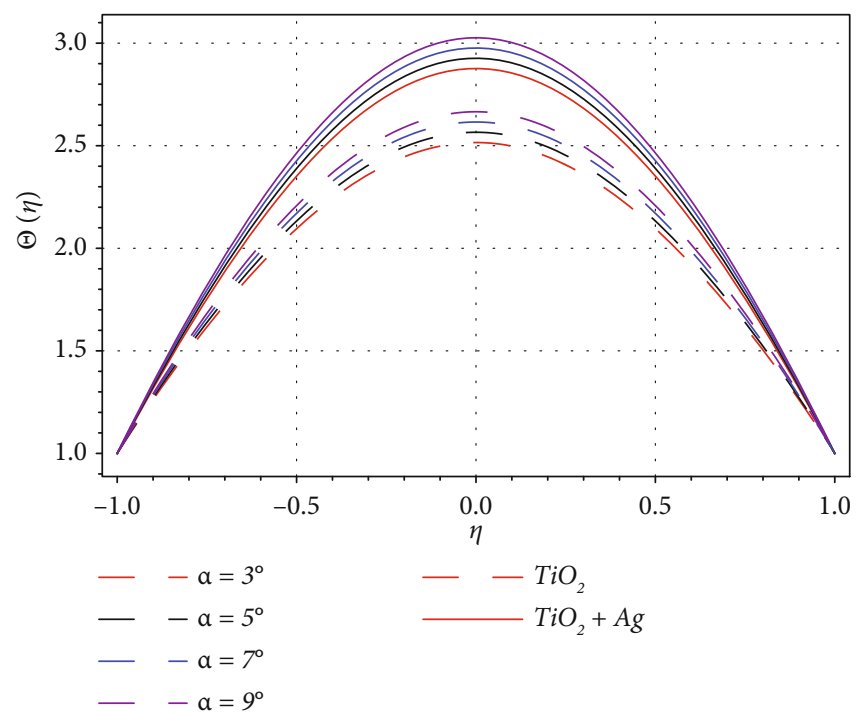

(c)

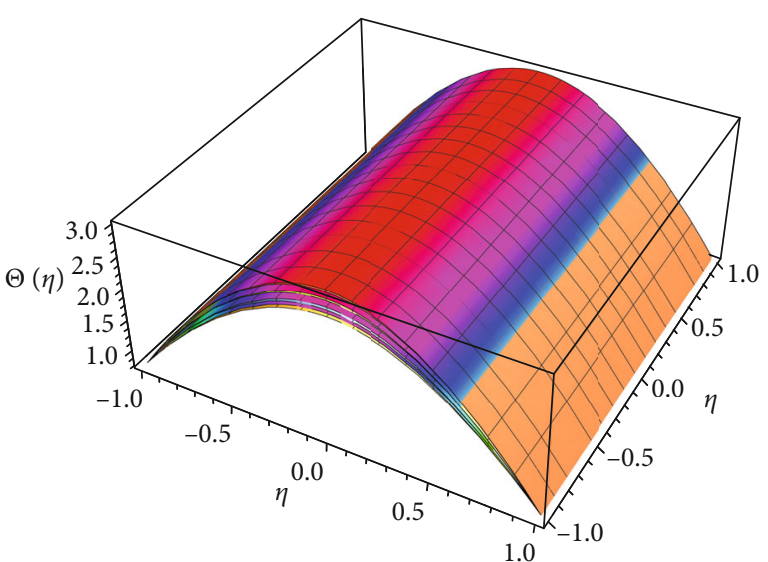

(b)

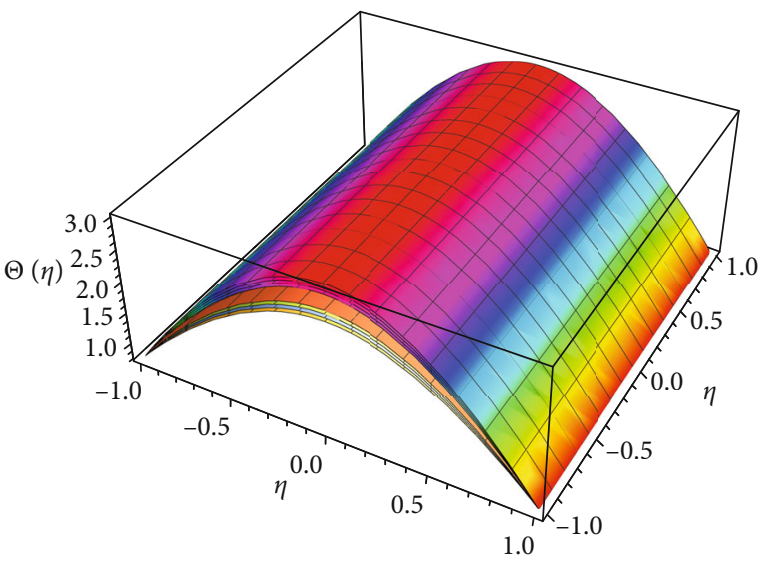

(d)

Figure 5: (a-d) $\Theta(\eta)$ versus $\alpha$.

be observed from Figures 3(a) and 3(b) while a reverse result is obtained in the contracting/divergent case because the growth in Reynolds number causes a decline in the fluid motion, in this case, that can be seen in Figures 3(c) and 3(d).

Figures 4(a)-4(d) indicate the influence of $\left(k^{*}\right)$ on $F(\eta)$ in extending/convergent and contracting/divergent cases. The fluid motion decays as increasing the value of $\left(k^{*}\right)$, that is, fluid motion decline with the improvement in the values of $\left(k^{*}\right)$.

Figures 5(a)-5(d) and 6(a)-6(d) represent the special effects of $\alpha$ and $\left(\phi_{1}, \phi_{2}\right)$ temperature distribution $\Theta(\eta)$ for extending/converging and contracting/divergent cases.

The larger values of $\alpha$ augmented the temperature distribution in each case as shown in Figures 5(a)-5(d). The enlarging values of the parameters $\phi_{1}$ and $\phi_{2}$ in the specific domain enhance the temperature distribution and are revealed in Figures 6(a)-6(d). In each case, the accumulative growth provides the increasing effect, and this improvement is more effective using the hybrid nanofluids.

The comparison of the obtained results is compared with the available literature [3-5] and displayed in Figures 7(a) and 7 (b) considering diverging and converging cases of the channel. The closed agreement has been achieved while choosing the common parameter Re. The influence of the nanoparticle volume fraction versus the skin friction has been shown in Figures 7(c) and 7(d) for both cases. The augmentation in the values of $\phi_{1}, \phi_{2}$ improves the resistive force to rise the drag force at the upper and lower walls. The influence is relatively strong using the hybrid nanofluids.

The percentage increase in the heat transfer rate has been revealed in Figures $8(\mathrm{a})-8(\mathrm{~d})$. The values of the 


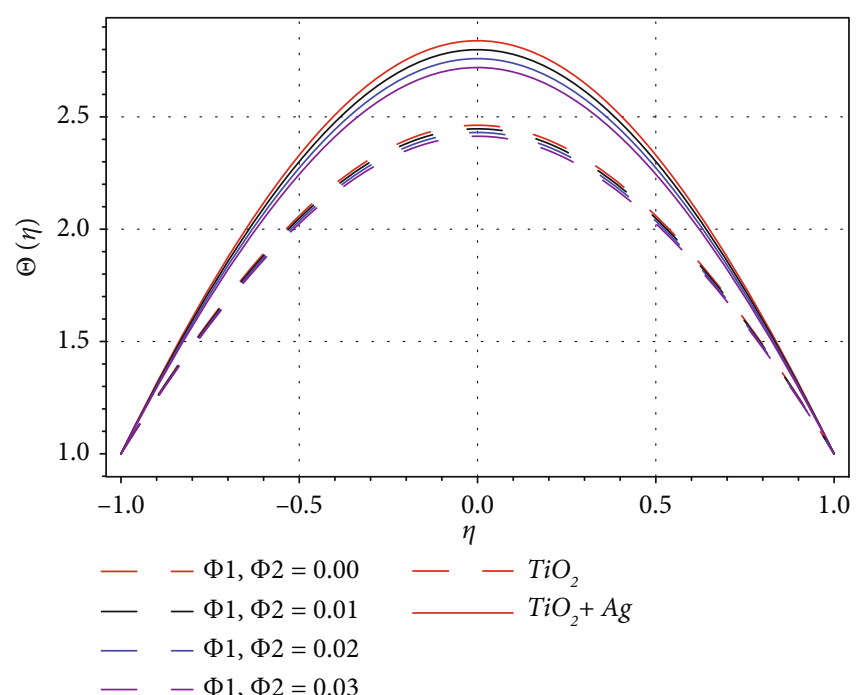

(a)

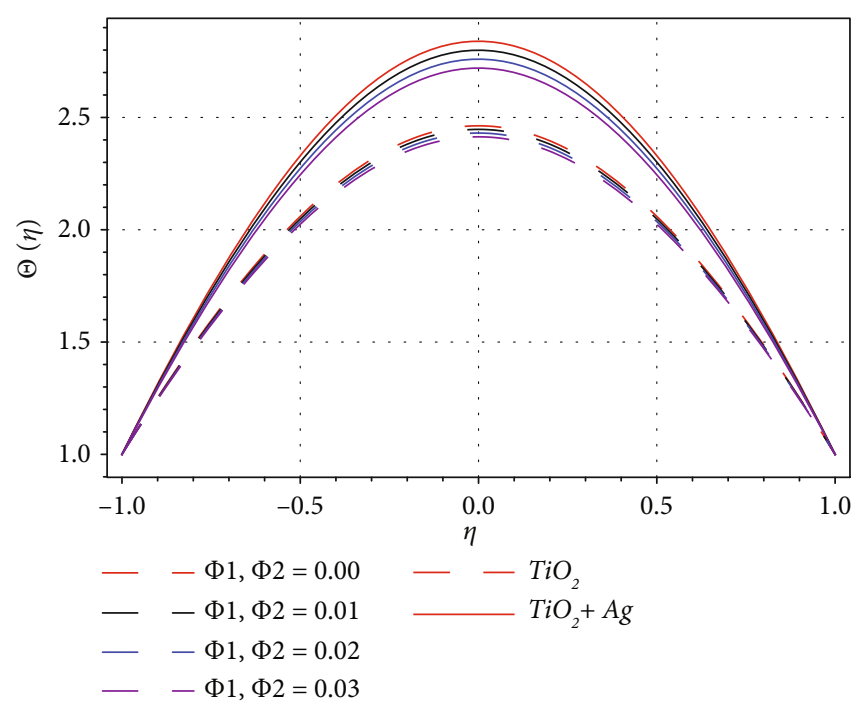

(c)

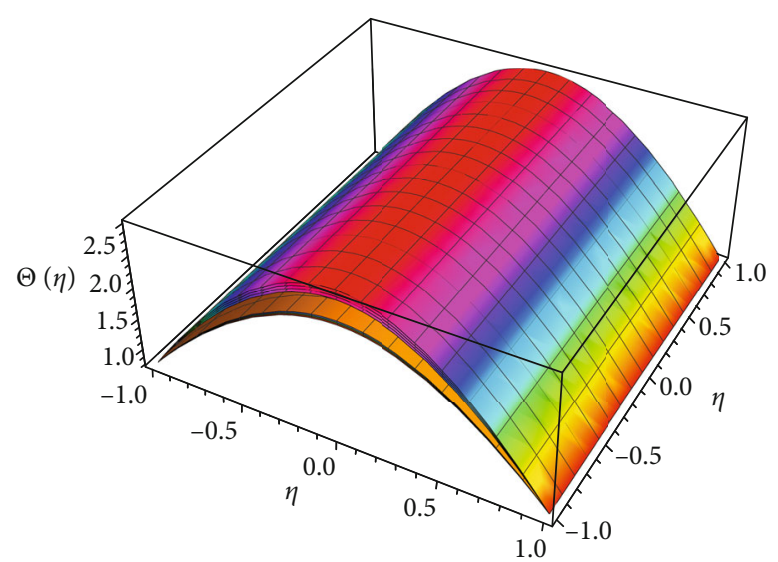

(b)

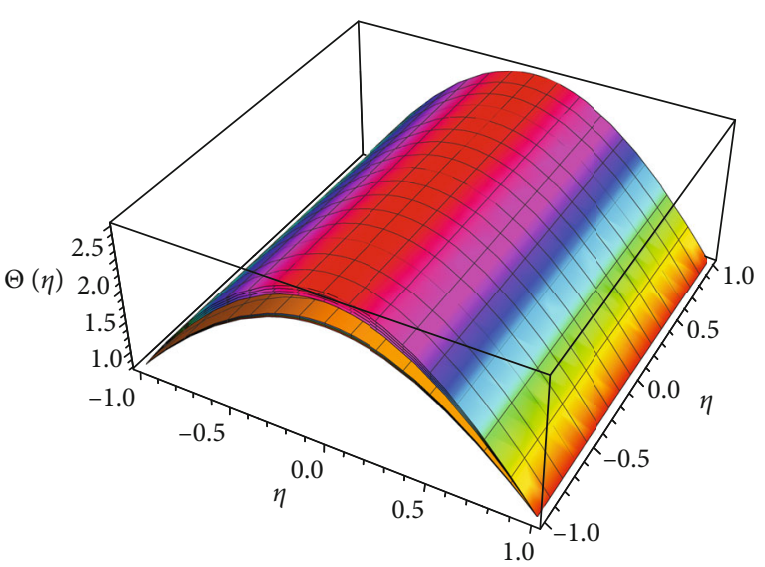

(d)

Figure 6: (a-d) $\Theta(\eta)$ versus $\phi_{1}, \phi_{2}$. 

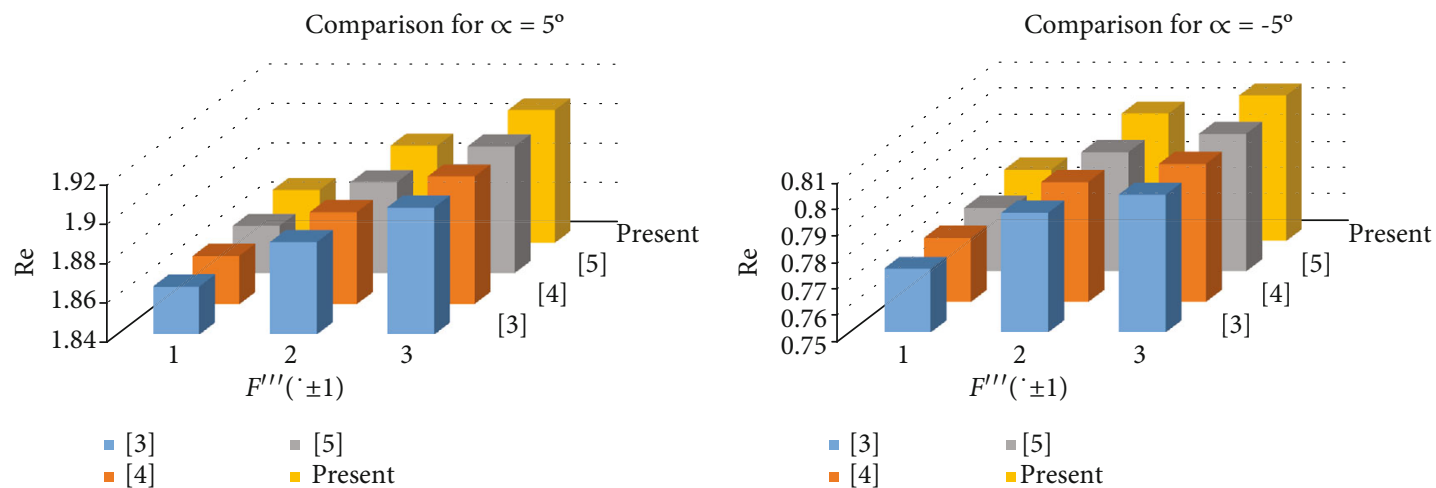

(a)
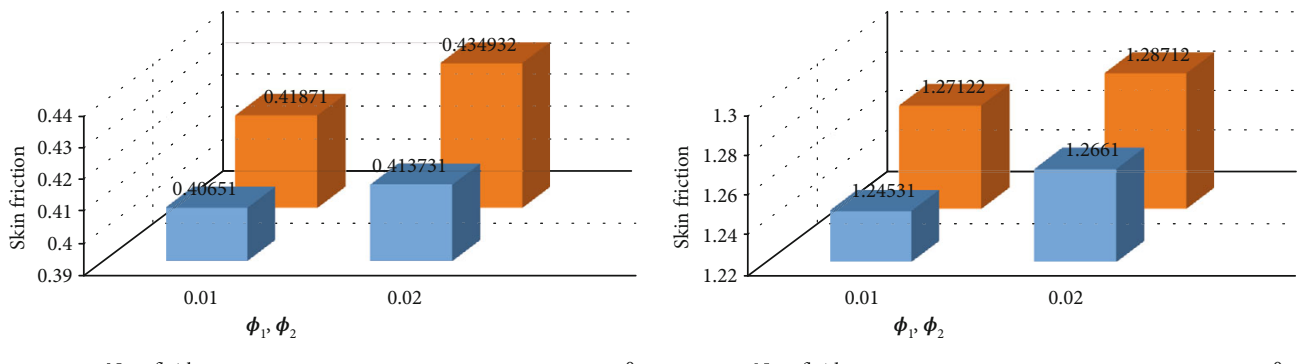

- Hybrid Nanofluid

(c)

In Nanofluid

(d)

FIGURE 7: (a-d) Matching of the current work with published literature [3-5] and $C f$ versus $\phi_{1}, \phi_{2}$.

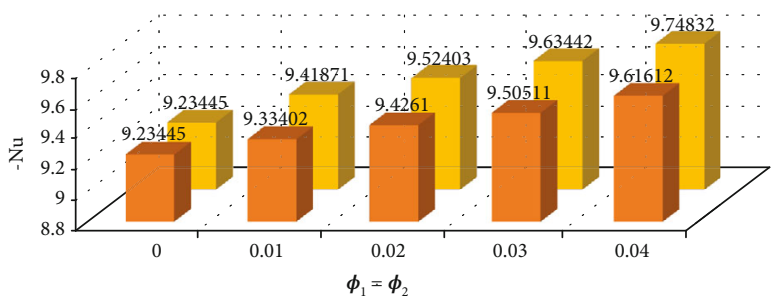

Nanofluid

Hybrid Nanofluid

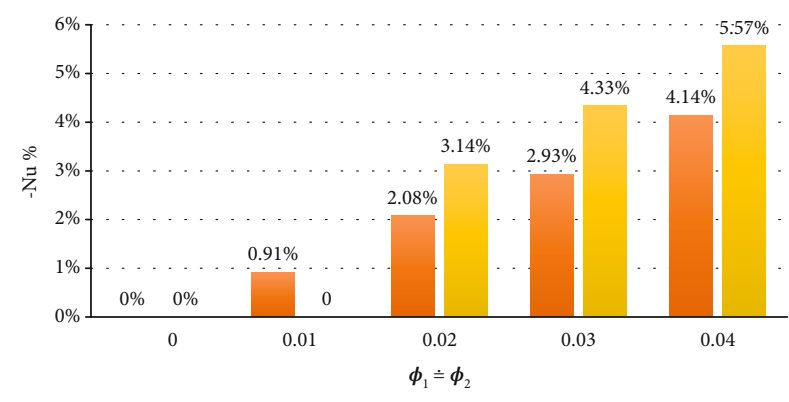

Nanofluid
Hybrid Nanofluid

(b)

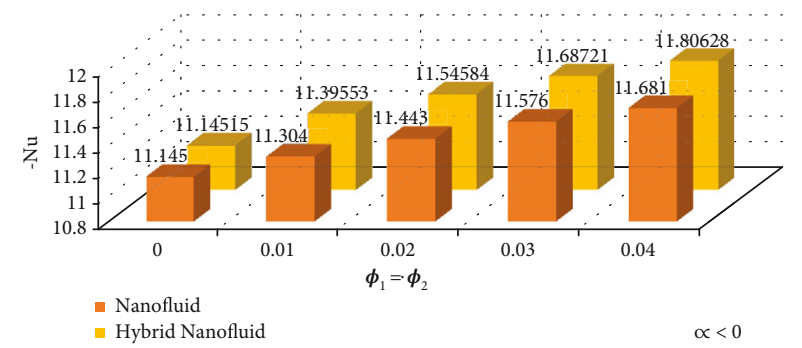

(c)

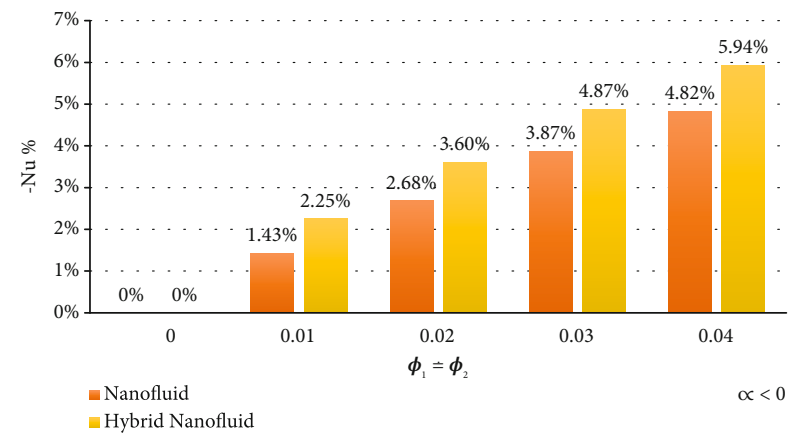

(d)

Figure 8: (a-d) Matching of the current work with published literature [3-5] and $C f$ versus $\phi_{1}, \phi_{2}$. 
nanoparticle volume fraction are used up to $3 \%$ as $\left(\phi_{1}, \phi_{2}\right.$ $=0.0,0.01,0.02,0.03)$. The comparative analysis of the nanofluid and hybrid nanofluid is shown in Figures 8(a) and 8 (c) for the diverging and converging cases of the channel, while the \% analysis has been performed in Figures 8(b) and $8(\mathrm{~d})$ for the same cases, respectively. The \% increase is more appropriate by using the hybrid nanofluids in both $\alpha$ $>0$ and $\alpha<0$.

\section{Conclusions}

The current article explores the blood flow across a converging/diverging channel with stretchable/shrinkable walls with couple stress for the application of drug delivery. The consequences of the converging/diverging parameter, couple stress parameter, and solid nanoparticles are incorporated.

To the best of our knowledge and belief, the converging/diverging channel including blood as a base fluid does not exist in the existing literature. Furthermore, the work also extended using the $\mathrm{Ag}$ and $\mathrm{TiO}_{2}$ hybrid nanofluid. Couple stress terminologies are also used as a novelty in the current problem.

The key conclusions of the existing study are as follows:

(i) The rising values of solid nanoparticles $\phi_{1}, \phi_{2}$ enhance the energy transmission rate, and the impact is relatively larger in the case of hybrid nanofluid

(ii) The velocity field declines with the accumulative values of the parameters $\phi_{1}, \phi_{2}$, and $\operatorname{Re}$

(iii) The couple stress parameter $k^{*}$ has a significant role in blood flow analysis and declines the hybrid nanofluid motion

(iv) $\mathrm{TiO}_{2}+$ Ag hybrid nanofluids have an important role in the Escherichia coli culture to evaluate their antibacterial strength

(v) The \% analysis shows that hybrid nanofluids are more efficient for heat transfer analysis

(vi) The $\mathrm{pH}$ values improve with the increment in heat transfer. That is why the purpose of the recent study is to use the $\mathrm{TiO}_{2}+\mathrm{Ag}$ hybrid nanofluids for medication

\section{Data Availability}

All the relevant data exist in the manuscript.

\section{Conflicts of Interest}

The authors declare that they have no conflict of interest.

\section{Acknowledgments}

The Deanship of Scientific Research (DSR) at King Abdulaziz University, Jeddah, Saudi Arabia, has funded this project, under grant no. KEP-37-130-42.

\section{References}

[1] M. Sheikholeslami, D. D. Ganji, H. R. Ashorynejad, and H. B. Rokni, "Analytical investigation of Jeffery-Hamel flow with high magnetic field and nanoparticle by Adomian decomposition method," Applied Mathematics and Mechanics, vol. 33, no. 1, pp. 25-36, 2012.

[2] M. Turkyilmazoglu, "Extending the traditional Jeffery-Hamel flow to stretchable convergent/divergent channels," Computers and Fluids, vol. 100, pp. 196-203, 2014.

[3] A. S. Dogonchi and D. D. Ganji, "Investigation of MHD nanofluid flow and heat transfer in a stretching/shrinking convergent/divergent channel considering thermal radiation," Journal of Molecular Liquids, vol. 220, pp. 592-603, 2016.

[4] W. F. Xia, M. I. Khan, S. U. Khan, F. Shah, and M. I. Khan, "Dynamics of unsteady reactive flow of viscous nanomaterial subject to Ohmic heating, heat source and viscous dissipation," Ain Shams Engineering Journal, vol. 2021, 2021.

[5] A. Mishra, A. K. Pandey, A. J. Chamkha, and M. Kumar, "Roles of nanoparticles and heat generation/absorption on MHD flow of $\mathrm{Ag}-\mathrm{H}_{2} \mathrm{O}$ nanofluid via porous stretching/shrinking convergent/divergent channel," Journal of the Egyptian Mathematical Society, vol. 28, no. 1, 2020.

[6] S. Zuhra, N. S. Khan, Z. Shah, S. Islam, and E. Bonyah, "Simulation of bioconvection in the suspension of second grade nanofluid containing nanoparticles and gyrotactic microorganisms," AIP Advances, vol. 8, no. 10, p. 105210, 2018.

[7] S. M. Moghimi, A. C. Hunter, and J. C. Murray, "Nanomedicine: current status and future prospects," The FASEB Journal, vol. 19, pp. 311-330, 2005.

[8] Z. Shah, M. Sheikholeslami, Ikramullah, and P. Kumam, "Influence of nanoparticles inclusion into water on convective magneto hydrodynamic flow with heat transfer and entropy generation through permeable domain," Case Studies in Thermal Engineering, vol. 21, p. 100732, 2020.

[9] M. G. Reddy and O. D. Makinde, "Magnetohydrodynamic peristaltic transport of Jeffrey nanofluid in an asymmetric channel," Journal of Molecular Liquids, vol. 223, pp. 1242-1248, 2016.

[10] I. Shahzadi and S. Bilal, "A significant role of permeability on blood flow for hybrid nanofluid through bifurcated stenosed artery: drug delivery application," Computer Methods and Programs in Biomedicine, vol. 187, p. 105248, 2020.

[11] S. Nadeem and S. Ijaz, "Theoretical analysis of metallic nanoparticles on blood flow through stenosed artery with permeable walls," Physics Letters A, vol. 379, pp. 542-554, 2015.

[12] R. Ellahi, S. U. Rahman, S. Nadeem, and N. S. Akbar, "Blood flow of nanofluid through an artery with composite stenosis and permeable walls," Applied Nanoscience, vol. 48, no. 4, pp. 919-926, 2013.

[13] S. Nadeem and S. Ijaz, "Theoretical examination of nanoparticles as a drug carrier with slip effects on the wall of stenosed arteries," International Journal of Heat and Mass Transfer, vol. 93, pp. 1137-1149, 2016.

[14] S. Dinarvand, M. Nademi Rostami, R. Dinarvand, and I. Pop, "Improvement of drug delivery micro-circulatory system with a novel pattern of $\mathrm{CuO}-\mathrm{Cu} / \mathrm{blood}$ hybrid nanofluid flow towards a porous stretching sheet," International Journal of Numerical Methods for Heat \& Fluid Flow, vol. 29, no. 11, pp. 4408-4429, 2019.

[15] B. Bahrami, M. Hojjat-Farsangi, H. Mohammadi et al., "Nanoparticles and targeted drug delivery in cancer therapy," Immunology Letters, vol. 190, pp. 64-83, 2017. 
[16] L. Liu, P. Miao, Y. Xu, Z. Tian, Z. Zou, and G. Li, "Study of $\mathrm{Pt} / \mathrm{TiO}_{2}$ nanocomposite for cancer-cell treatment," Journal of Photochemistry and Photobiology B: Biology, vol. 98, no. 3, pp. 207-210, 2010.

[17] H. Shojaie Chahregh and S. Dinarvand, " $\mathrm{TiO}_{2}-\mathrm{Ag} /$ blood hybrid nanofluid flow through an artery with applications of drug delivery and blood circulation in the respiratory system," International Journal of Numerical Methods for Heat \& Fluid Flow, vol. 30, no. 11, pp. 4775-4796, 2020.

[18] V. K. Stokes, "Couple Stresses in Fluids," in Theories of Fluids with Microstructure, pp. 34-80, Springer, Berlin, Heidelberg, 1984.

[19] L. M. Srivastava, "Flow of couple stress fluid through stenotic blood vessels," Journal of Biomechanics, vol. 18, no. 7, pp. 479-485, 1985.

[20] M. Devakar and T. K. V. Iyengar, "Stokes' problems for an incompressible couple stress fluid," Nonlinear Analysis: Modelling and Control, vol. 13, no. 2, pp. 181-190, 2008.

[21] A. Saeed, A. Alsubie, P. Kumam, S. Nasir, T. Gul, and W. Kumam, "Blood based hybrid nanofluid flow together with electromagnetic field and couple stresses," Scientific Reports, vol. 11, no. 1, pp. 1-18, 2021.

[22] M. W. Ahmad, P. Kumam, Z. Shah et al., "Darcy-Forchheimer MHD couple stress 3D nanofluid over an exponentially stretching sheet through Cattaneo-Christov convective heat flux with zero nanoparticles mass flux conditions," Entropy, vol. 21, no. 9, p. 867, 2019.

[23] T. Gul, A. Qadeer, W. Alghamdi, A. Saeed, S. M. Mukhtar, and M. Jawad, "Irreversibility analysis of the couple stress hybrid nanofluid flow under the effect of electromagnetic field," International Journal of Numerical Methods for Heat \& Fluid Flow, vol. ahead-of-print, 2021.

[24] T. Gul, B. Ali, W. Alghamdi et al., "Mixed convection stagnation point flow of the blood based hybrid nanofluid around a rotating sphere," Scientific Reports, vol. 11, no. 1, 2021.

[25] S. J. Liao, "An explicit, totally analytic approximate solution for Blasius' viscous flow problems," International Journal of Non-Linear Mechanics, vol. 34, no. 4, pp. 759-778, 1999.

[26] S. Liao, "An optimal homotopy-analysis approach for strongly nonlinear differential equations," Communications in Nonlinear Science and Numerical Simulation, vol. 15, no. 8, pp. 2003-2016, 2010.

[27] T. Gul, R. S. Gul, W. Noman et al., "CNTs-Nanofluid flow in a rotating system between the gap of a disk and cone," Physica Scripta, vol. 95, no. 12, p. 125202, 2020.

[28] T. Gul, M. Z. Ullah, A. K. Alzahrani, Z. Zaheer, and I. S. Amiri, "MHD thin film flow of kerosene oil based CNTs nanofluid under the influence of Marangoni convection," Physica Scripta, vol. 95, no. 1, article 015702, 2020.

[29] A. Saeed and T. Gul, "Bioconvection Casson nanofluid flow together with Darcy-Forchheimer due to a rotating disk with thermal radiation and Arrhenius activation energy," $S N$ Applied Sciences, vol. 3, no. 1, 2021.

[30] A. Khan, A. Saeed, A. Tassaddiq et al., "Bio-convective micropolar nanofluid flow over thin moving needle subject to Arrhenius activation energy, viscous dissipation and binary chemical reaction," Case Studies in Thermal Engineering, vol. 25, p. 100989, 2021.
[31] F. Ahmad, T. Gul, I. Khan et al., "MHD thin film flow of the Oldroyd-B fluid together with bioconvection and activation energy," Case Studies in Thermal Engineering, vol. 27, article 101218, 2021.

[32] A. K. Alzahrani, M. Z. Ullah, A. S. Alshomrani, and T. Gul, "Hybrid nanofluid flow in a Darcy-Forchheimer permeable medium over a flat plate due to solar radiation," Case Studies in Thermal Engineering, vol. 26, article 100955, 2021. 